\title{
EDUCACIÓN PARA LA PAZ
}

\author{
Monclús, Antonio y Sabán, Carmen Editorial Síntesis, S. A. \\ Lic. Illiana Rubí Juárez López* \\ ijuarez@lasallep.edu.mx
}

La idea general del libro es brindarnos un panorama amplio sobre lo que es la paz y que ésta debe ser el estado ideal entre los diversos pueblos de la tierra. La mejor manera de llegar a ella es por medio de la educación.

Los autores utilizan diversas perspectivas para que el lector entienda las diversas concepciones y motivos por los cuales debemos de alcanzar la paz, exponiendo algunas de las consecuencias que han sufrido las sociedades de diferentes países como muerte, hambre, destrucción, mutilación, etc., por falta de PAZ.

Una de las perspectivas que los autores tocan en la psicológica, respaldada por los diversos estudios de Sigmund Freud y Erich Fromm, entre otros. La base de dichos estudios está en que todos los seres humanos tenemos dos impulsos, el Eros o instinto de vida y el Thánatos o instinto de muerte, ambos instintos forman parte de todos los seres humanos, es por eso la importancia de Educar para la Paz, para que el instinto de muerte sea derrotado por instinto de vida; si enseñamos las tradiciones y costumbres de los demás pueblos y/o sociedades será complicado despreciarlas y por lo tanto generar guerra. El ser humano es el único ser vivo capaz de matar y aniquilar a otro ser vivo incluso de su misma especie sin ningún provecho racional, biológico ni económico, es por esta razón que la educación juega un papel importante, para poder reprimir el instinto de muerte y que impere el instinto de vida.

Otra de las perspectivas que el libro nos plantea es la sociocultural, en muchos pueblos se les enseña a los pequeños a odiar y matar por cuestiones que ellos aún no llegan a comprender, esto lleva a guerras entre países, etnias, regiones, etc. En muchos de estos casos los únicos beneficiados son los vendedores de armas surtidos por los mismos gobiernos de países que tienen economías de guerra. En este contexto, los escritores basados en diversos estudios de otros autores, nos plantean tres tipos de violencia: la directa, la estructural y en potencia.

Lederach, uno de los estudiosos que rescataron los autores, rescata el hecho de que el desarme debe ser el proceso de deshacer el sistema de guerra para llegar a un sistema de paz.

Un aspecto importante a destacar del libro es todo lo que comenta sobre la UNESCO, creada después de la Segunda Guerra Mundial con objetivos diversos pero todos dirigidos a temas educativos, entre ellos tener a la paz como una prioridad educativa, lo que ha llevado a que éste sea un tema de preocupación internacional para líderes.

Una estrategia que propone la UNESCO para fomentar la cultura de la paz es trabajar de 
forma conjunta con las instituciones e individuos para que todos podamos recibir una educación y formación apropiada con énfasis en aquellos temas que usualmente han sido discriminados por diversas razones y en diversas formas. Un tópico importante que también es preocupación de la organización es la situación de la mujer en diversas zonas del planeta, por lo que esta organización ha promovido una serie de acciones entre las cuales destaca la contribución de la mujer en la cultura de la paz.

Hay cuatro pilares que el libro destaca sobre los cuales debe de estar basada la educación a lo largo de la vida, y son: aprender a conocer, aprender a vivir y junto y con los otros, por último aprender a ser. Lo antes mencionado dará un nuevo impulso con el descubrimiento progresivo de los otros y otras, así como la puesta en práctica de proyectos comunes como forma eficaz de evitar o resolver los conflictos que puedan llegar a surgir.

La UNICEF juega un papel importante en la educación para la paz con los niños y niñas de todo el planeta, ya que es ella la principal gestora de que las instituciones y escuelas implementen los temas necesarios dentro de los planes de estudio para que los objetivos de paz de la UNESCO se cumplan.

El libro también destaca que los menos afortunados durante las guerras son siempre los niños, es por ellos la preocupación de educar a favor de la paz, en el cuadro 3.4 de la página 49 titulado Los niños, víctimas de la guerra podemos encontrar datos realmente alarmantes de las consecuencias que las guerras han dejado en estos.

\section{Comentario}

Muchos han sido los líderes a lo largo de los últimos 100 años que han buscado la paz dentro de los pueblos, todo ellos con la finalidad de poder convivir de forma armónica y pacífica, a través del diálogo y la no violencia. A pesar de vivir en un mundo globalizado pareciera que muchas personas no son conscientes de la realidad y necesidades de otros pueblos, es por ello que una de las preocupaciones UNESCO es la educación de los estudiantes desde pequeños.

El concepto de discriminación que la UNESCO establece me parece muy completo y claro, eso lo podemos leer en el cuadro 4.3 de la página 89 del libro, con el no podemos dar una idea de los puntos en los que más se deben de enfocar.

Leer este libro es una grata experiencia, el vocabulario es simple y nos permite conocer aspectos diversos puntos de vista o posiciones sobre la paz, es importante que entendamos que la educación empieza en el hogar y en la familia, pues ahí donde recibimos nuestras primeras lecciones de vida, por lo tanto es ahí donde podemos empezar a enseñar a nuestros niños y niñas a vivir en armonía y paz con todo nuestros semejantes. 